\title{
Evaluation of Drought Effect on Soybean Genotypes Mediated through PEG-6000 (Polyethylene Glycol)
}

\author{
Sumit N. Deshmukh*, Prashant N. Kolhe*, Manisha R. Kale, \\ Mrunalini D. Varne and Kiran Pawar
}

\author{
Mahatma Gandhi Mission's Institute of Biosciences and Technology, N-6 CIDCO, Main \\ Campus, Aurangabad, Maharashtra 431003, India
}

*Corresponding author

\section{A B S T R A C T}

\begin{tabular}{|l|}
\hline Ke y w o r d s \\
Drought Effect, \\
Soybean \\
Genotypes, PEG \\
\hline Article Info \\
\hline $\begin{array}{l}\text { Accepted: } \\
\text { 07 August } 2020 \\
\text { Available Online: } \\
\text { 10 September } 2020\end{array}$ \\
\hline
\end{tabular}

Drought is one of the most important stress that reduce the growth yield and development of crops. Soybean is the most important source of food, protein and oil and hence more research is essential to increase its yield under different conditions including stress. Developing drought tolerance and other abiotic stress resistance soybean cultivars is an important goal throughout the world. Germination is one of the main growth stage for seedling establishment and is dependent on moisture availability in soil. The experiment was carried out to evaluate the germination and other characteristics of six soybean genotypes (JS-335, JS-93-05, KDS-344, PUSA-20, MAUS-162andMACS-57) under four levels of osmotic stress (control, 5\%, 10\%, 15\%, 20\%). Polyethylene glycol (PEG) 6000 was used as osmoticum. This investigation was performed as factorial experiment under Completely Randomized Design (CRD). Germination and early growth was affected by drought stress. The observations were made on germination percentage, plant shoot length, shoot fresh weight, shoot dry weight, root length etc. the result indicated that the two soybean genotypes MAUS-162 and PUSA 20 exhibited tolerance against drought stress compared to other varieties. The variation among genotypes for germination and other biological parameter was found to be a reliable indicator to screen the drought tolerant genotypes at germination seedling stage in soybean.

\section{Introduction}

The soybean (Glycine max L.) belongs to the family leguminosae originated in south East Asia. Soybean is an industrial crop cultivated for oil and protein. Despite the relatively low oil content of the seed (about 20\% on moisture free basis) soybeans are the largest single source of edible oil and account for roughly $50 \%$ of the total oilseed production of the world. They can grow in wide range of soils, generally moist alluvial soils with good organic content. The key advantages of soybean are its high protein content, vitamins, minerals and insoluble fibers. Soybean is viewed as equivalent to creature nourishments in protein quality (13). Soybean is used in variety of industries providing products for human consumption, livestock feed and industrial purpose. Soybean seed consist of 
$35 \%$ carbohydrates, $5 \%$ ash, $40 \%$ protein and $20 \%$ oil; and is major source protein and oil for commercial products (15). In the survey of soybean crop for the season of 2018-19 the total area under soybean for 2018 was 108.396 lakh hectares. The area has increased by 6.83 lakh hectare $(6.7 \%)$ as compared to previous year (SOPA, Indore MP). The government area estimate is around 113.339 lakh ha. The estimated total production of soybean crop for all India for the year 2018 is 114.832 lakh tones which is higher by 31.275 lakh tones (37.4\%) as compared to kharif 2017 this could be highest in last five years (SOPA, Indore MP). Improvement in the yield of soybean grain and quality of soybean oil are possible by use of new research methodologies and by exploitation of recent advances in biology (14).

Drought is one of the most important environmental stress affect the growth and development there by reducing the yield to greater extent in many crops. Among the oilseeds soybean plays key role as it contains high protein content and it is highly sensitive to drought stress. All root, shoot and physiological parameters were inversely correlated with the soil moisture level. Adverse effect of drought on soybean cultivars is found to be more evident (27). To identify the tolerant genotypes at early growth stages the soybean varieties are subjected to different PEG concentrations (17). Biochemical parameters such as osmolytes and antioxidant enzymes provide useful tools for identification of drought tolerant wheat cultivars at seedling stage (30).

\section{Materials and Methods}

\section{Biological material}

The six soybean genotypes (JS-335, JS-93-05, KDS-344, PUSA-20, MAUS-162 and MACS57) were collected from National seed corporation office Aurangabad and MAHABEEJ Akola. All these genotypes were selected as base population for experiment. This investigation was performed as factorial experiment under Completely Randomized Design (CRD) with five replications.

\section{Chemical Treatment}

Seeds from all varieties were surface sterilized with $1 \% \mathrm{Hgcl} 2$ and rinsed twice in distilled water. After that seeds were treated with different concentrations of PEG 6000 (Polyethylene Glycol) 100ml of 5\%, 10\%, $15 \%$ and $20 \%$ along with control $(100 \mathrm{ml}$ of water).To avoid contamination all the process carried out in laminar air flow.

\section{Data collection and statistical analysis}

After 7-10 days observations were made on germination percentage and other biological parameter such as plant shoot length, root length, shoot fresh weight, root fresh weight, shoot dry weight were recorded on 2025DAS.

\section{Results and Discussion}

\section{Effect of drought stress on germination}

The data on seed germination was influenced by PEG concentrations as compared to control and presented in table 1 and fig. 1 respectively. The highest germination percentage was found in MAUS-162 and PUSA 20 at concentration ranges from 5\% to $20 \%$ and lowest germination percentage was found in KDS-344. Other genotype shows intermediate result to germination. It is doubtful that the seed germination test could be used as a reliable procedure for identifying drought tolerant cultivar because it tended to reflect differences in seed quality and had no relation to field performance (20). Drought is 
one of the most important tension in reducing the growth and production of plant. It can affect many aspects of plant metabolism and growth because this tension reduces germination rate and percentage and finally delays establishment of plantlets (31).According to the effect of PEG content on the germination speed resulted data revealed that increasing PEG\% associated with decrease in germination rate with decreasing percentage. Drought stress had different effects on the physiology of the soybean cultivars the vegetative effects were more obvious at the late stages of plants life cycle of soybean cultivars which will presumably affect on the yield component trait and consequence the expected yield (16). Water deficit stress significantly reduced the rate and percentage of germination and emergence and early seedling growth in sorghum cultivars (28). Water potential significantly reduced germination percent, germination rate, root and shoot length, seed vigour in corn (2).

\section{Effect of drought stress on plant shoot length}

The effects of different PEG concentration on shoot length are shown in table 2 and Fig. 2, respectively. At 5\% PEG concentration shoot length was highest in MAUS-162 (5.72) and PUSA-20 (5.10) and at 20\% PEG concentration both MAUS 162 and PUSA 20 shows highest shoot length 4.47 and 4.72 respectively. Lowest shoot length was found in JS 335 (3.82) and KDS 344 (4.14) at 20\% PEG concentration. Decreased in osmotic potential caused a reduction in germination percentage and seedling growth in triticale (25). There is significant differences observed in germination percentage, coleoptile length, shoot root length and seed vigor index in wheat cultivars for drought tolerance (26). The reduction in all biological parameters regarding seedling growth was affected by different PEG concentrations was noticed in barley cultivars (18). Also total leaf area, specific leaf weight and specific leaf area decreased with stress level increased. Grain yield were significantly lower by stress when it was applied at the booting stage in sorghum (29). Rate of germination vigour index, shoot and root length and seedling dry weight of all wheat genotypes were delayed with the increment of water stress induced by PEG (6).

\section{Effect of drought stress on shoot fresh weight}

Reduction in fresh weight of all cultivars of soybean was observed because of water stress. The results indicated that fresh weight of seedling decreased linearly as the PEG concentration increased from $5 \%$ to $20 \%$ respectively. Lowest fresh weight of seedlings was observed in KDS-344 (0.48) at 15\% and (0.51) at $20 \%$ PEG concentrations. Some of the workers in their in vitro studies on wheat concluded that osmotic stress significantly reduced the seed germination, shoot root length, fresh and dry weight in wheat genotypes (9) (Fig. 3). Second after KDS 344 other varieties JS 335 and JS 93-05 and MACS 57 shows $0.64,0.67$ and 0.61 shoot fresh weight at 20\% PEG concentration respectively. The maximum shoot fresh weight was found in MAUS 162 (0.87) and PUSA $20(0.83)$ at $20 \%$ concentration. Similar results were observed in maize cultivars for germination percentage and rate, shoot and root length, root number and shoot and root fresh weight. Increased PEG concentration decreased germination percentage in maize (1). All PEG treatments significantly reduce germination and retarded seedling early growth in maize. Drought resistant cultivar in maize were easily screened by using PEG and using seedling trait is a cost effective approach in achieving rapid screening for tolerant or sensitive maize genotypes in short time (8). Significant positive correlation exist between the 
important growth parameter like rate of germination percentage, final germination percentage, shoot dry weight, root dry weight and vigor index in wheat genotypes (10).
Variation in germination, root and shoot length, total fresh weight, total dry weight under several PEG treatments was observed in rice genotypes (7).

Table.1 Effect of drought stress on seed germination percentage

\begin{tabular}{|c|c|c|c|c|c|c|}
\hline \multirow{2}{*}{ Treatment } & \multicolumn{7}{|c|}{ Soybean varieties (Germination \%) } \\
\cline { 2 - 7 } & JS 335 & JS 93-05 & KDS 344 & MAUS 162 & MACS 57 & PUSA 20 \\
\hline Control & 80 & 100 & 100 & 100 & 100 & 100 \\
\hline $\mathbf{5 \%}$ & 100 & 80 & 100 & 100 & 60 & 100 \\
\hline $\mathbf{1 0 \%}$ & 80 & 80 & 60 & 80 & 60 & 100 \\
\hline $\mathbf{1 5 \%}$ & 60 & 60 & 80 & 100 & 80 & 80 \\
\hline $\mathbf{2 0 \%}$ & 80 & 60 & 60 & 80 & 80 & 100 \\
\hline
\end{tabular}

Table.2 Effects of drought stress on plant shoot length

\begin{tabular}{|c|c|c|c|c|c|c|}
\hline \multirow{2}{*}{ Treatment } & \multicolumn{7}{|c|}{ Soybean varieties (shoot length) } \\
\cline { 2 - 7 } & JS 335 & JS 93-05 & KDS 344 & MAUS 162 & MACS 57 & PUSA 20 \\
\hline Control & 4.46 & 4.78 & 4.28 & 5.92 & 4.7 & 5.32 \\
\hline $\mathbf{5 \%}$ & 4.54 & 4.64 & 4.18 & 5.72 & 4.42 & 5.1 \\
\hline $\mathbf{1 0 \%}$ & 4.42 & 4.6 & 4.03 & 5.38 & 4.34 & 5.04 \\
\hline $\mathbf{1 5 \%}$ & 4.28 & 4.44 & 4.12 & 4.82 & 4.2 & 4.88 \\
\hline $\mathbf{2 0 \%}$ & 3.82 & 4.18 & 4.14 & 4.47 & 4.22 & 4.72 \\
\hline
\end{tabular}

Table.3 Effect of drought stress on plant shoot fresh weight

\begin{tabular}{|c|c|c|c|c|c|c|}
\hline \multirow{2}{*}{ Treatment } & \multicolumn{7}{|c|}{ Soybean varieties (shoot fresh weight) } \\
\cline { 2 - 8 } & JS 335 & JS 93-05 & KDS 344 & MAUS 162 & MACS 57 & PUSA 20 \\
\hline Control & 1.4 & 1.47 & 1.6 & 1.98 & 1.83 & 1.85 \\
\hline $\mathbf{5 \%}$ & 0.97 & 0.87 & 0.84 & 1.43 & 0.67 & 0.98 \\
\hline $\mathbf{1 0 \%}$ & 0.81 & 0.73 & 0.56 & 1.18 & 0.7 & 0.95 \\
\hline $\mathbf{1 5 \%}$ & 0.74 & 0.8 & 0.48 & 0.91 & 0.68 & 0.89 \\
\hline $\mathbf{2 0 \%}$ & 0.64 & 0.67 & 0.51 & 0.87 & 0.61 & 0.83 \\
\hline
\end{tabular}

Table.4 Effect of drought stress on shoot dry weight

\begin{tabular}{|c|c|c|c|c|c|c|}
\hline \multirow{2}{*}{ Treatment } & \multicolumn{6}{|c|}{ Soybean varieties (shoot dry weight) } \\
\cline { 2 - 7 } & JS 335 & JS 93-05 & KDS 344 & MAUS 162 & MACS 57 & PUSA 20 \\
\hline Control & 0.755 & 0.475 & 0.675 & 0.835 & 0.721 & 0.84 \\
\hline $\mathbf{5 \%}$ & 0.098 & 0.086 & 0.084 & 0.181 & 0.067 & 0.099 \\
\hline $\mathbf{1 0 \%}$ & 0.051 & 0.074 & 0.077 & 0.148 & 0.07 & 0.094 \\
\hline $\mathbf{1 5 \%}$ & 0.057 & 0.068 & 0.071 & 0.124 & 0.05 & 0.09 \\
\hline $\mathbf{2 0 \%}$ & 0.066 & 0.08 & 0.093 & 0.0988 & 0.066 & 0.092 \\
\hline
\end{tabular}


Table.5 Effect of drought stress on root length

\begin{tabular}{|c|c|c|c|c|c|c|}
\hline \multirow{2}{*}{ Treatment } & \multicolumn{7}{|c|}{ Soybean varieties (root length) } \\
\cline { 2 - 8 } & JS 335 & JS 93-05 & KDS 344 & MAUS 162 & MACS 57 & PUSA 20 \\
\hline Control & 4.3 & 4.52 & 4.6 & 5.05 & 3.15 & 4.35 \\
\hline $\mathbf{5 \%}$ & 3.45 & 3.8 & 3.65 & 4.55 & 3.6 & 3.55 \\
\hline $\mathbf{1 0 \%}$ & 2.95 & 3.3 & 3.1 & 4.38 & 3.25 & 4.5 \\
\hline $\mathbf{1 5 \%}$ & 3.1 & 3.7 & 3.5 & 3.87 & 2.8 & 4.2 \\
\hline $\mathbf{2 0 \%}$ & 2.5 & 2.24 & 3.12 & 4.1 & 2.85 & 4 \\
\hline
\end{tabular}

Fig.1 Effect of drought stress on seed germination percentage

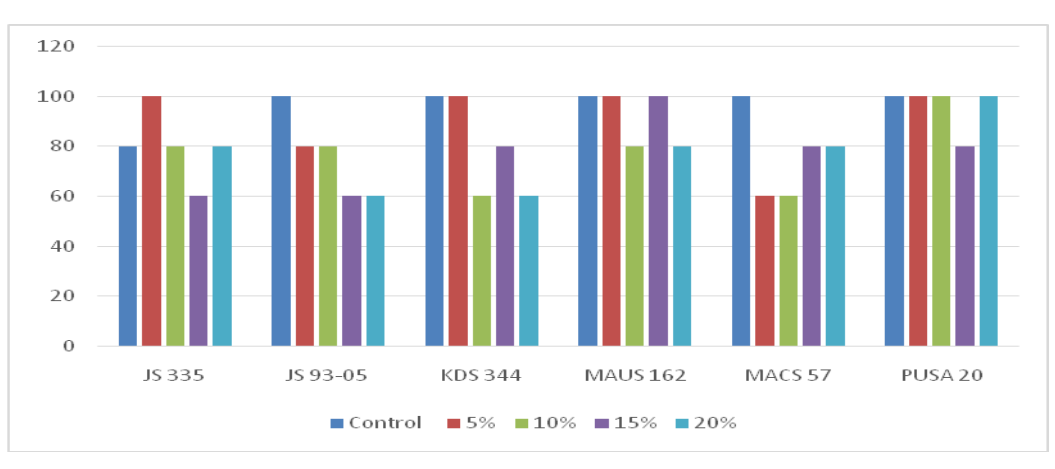

Fig.2 Effect of drought stress on plant shoot length

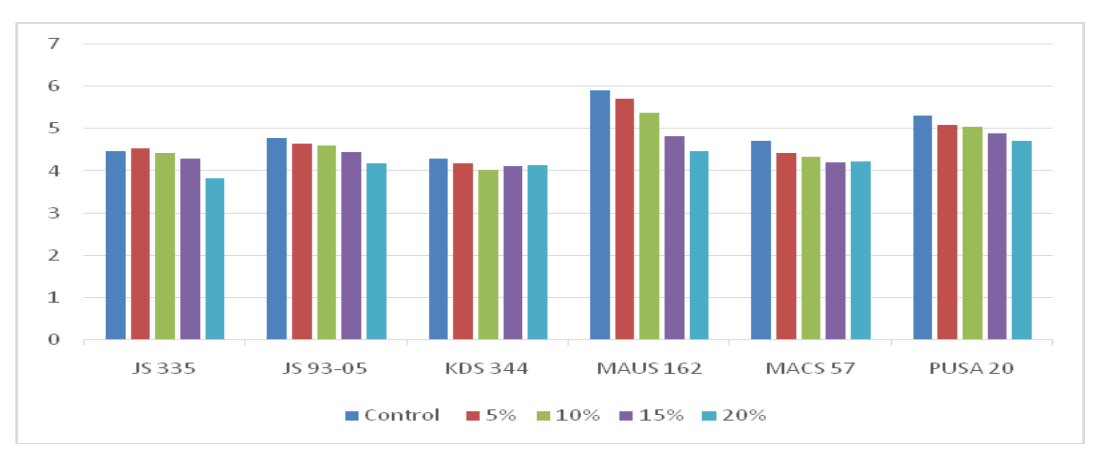

Fig.3 Effect of drought stress on plant shoot fresh weight

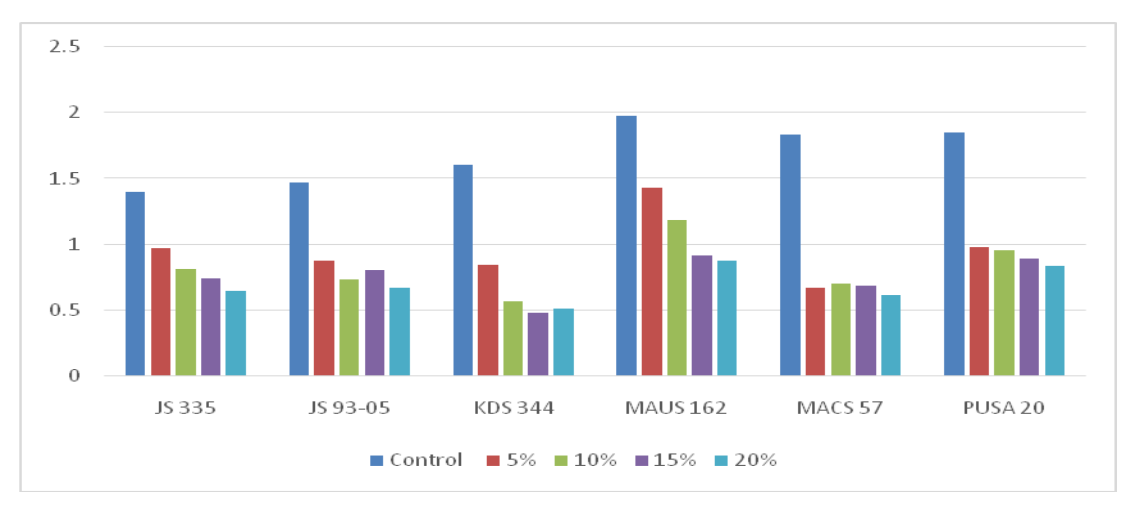


Fig.4 Effect of drought stress on shoot dry weight

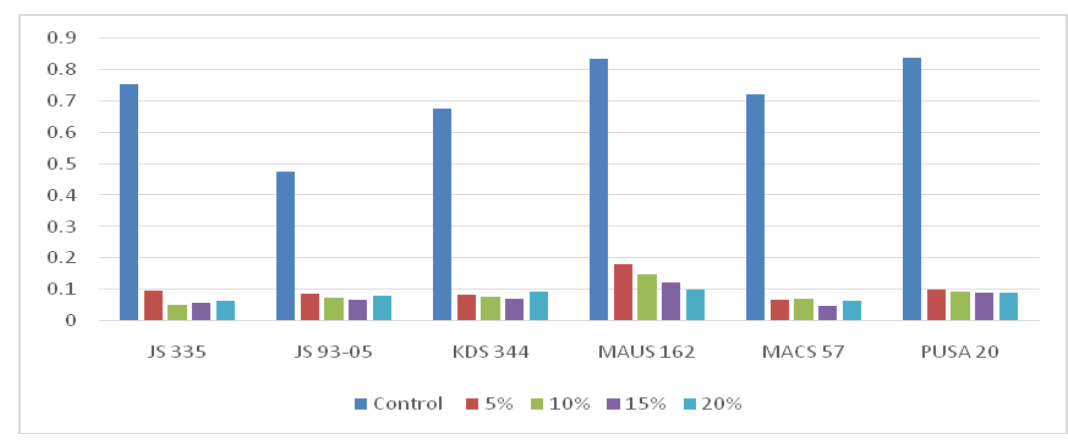

Fig.5 Effect of drought stress on root length



Effect of drought stress on shoot dry weight

Shoot dry weight was significantly influenced by the interaction effect of water stress and soybean genotypes. The variable result was observed in all soybean genotypes. The shoot dry weight was higher at control in all varieties ranges from 0.755 in JS 335 to 0.835 in MAUS 57. At 20\% PEG concentration shoot dry weight was highest in MACS 162 (0.098) and PUSA 20 (0.092) (Fig. 4). The soybean genotypes MAUS 162 and PUSA 20 shows good shoot dry weight at all PEG concentration as compare to other genotypes. Lowest dry weight was observed in MACS 57 $(0.050)$ at $15 \%$ PEG concentration. The shoot dry weight was reduced with increased water stress. After that the varieties JS 335, JS 9305 and MACS 57 shows intermediate response to all PEG concentrations. Similar result of decrease in fresh weight, dry weight, and relative water content was observed in wheat varieties (19). The impact of osmotic stress on various biological parameters was checked in black gram. The various osmotic potentials generated showed significant decrease in germination and seedling growth (24).Germination and early growth were affected by drought stress. Decreasing water potential or increasing moisture stress adversely affect germination and all seedling growth related characters in soybean genotypes (5). Increasing the stress strength of PEG caused a remarkable decrease in the early seedling fresh and dry weight of Medicago sativa (4). Drought significantly affected germination as well all other associated traits. Significant genetic variability in relation to genotypic performance under drought stress was observed in chickpea (11). 


\section{Effect of drought stress on root length}

Reduction in the root length of all cultivars of soybean was observed because of water stress the results indicated that root length of seedling decreased linearly as the PEG concentration increased from 10 to $20 \%$. The highest root length was observed in MAUS162 (4.55) and PUSA-20 (3.55) at 5\% PEG concentration. Lowest root length was observed in JS-335 (2.50) at 20\% PEG concentration. All other varieties shows variable results for root length. Drought stress can inhibit sown seeds and manipulate germination parameters in soybean cultivars germination ratio, root elongation decreased as PEG concentration increased (21). A remarkable reduction was noticed in tomato germplasm in root and shoot length with increasing PEG concentration (23). In vivo screening of soybean genotypes provides simple and quick identification of lines with higher drought tolerance (3). Water stress treatments significantly influenced the emergence percentage, promptness index, germination stress tolerance index, plant height stress index, root length stress index, primary root length and seed vigour of different maize cultivar (22). Many workers reported that mustard is sensitive to water stress occurred during seed germination. Seed germination and early seedling growth of mustard were influenced by different water stress levels (12) (Fig. 5).

In conclusion the present study from all the observations recorded on different biological parameters we can concluded that out of six soybean varieties MAUS 162 performed better under drought conditions and hence can be declared as drought tolerant variety. After that PUSA 20 also had good result for all observations. In general reduction in all early growth stages occurs due to increase PEG concentrations. JS 335, KDS 344 and MACS
57 genotypes of soybean were regarded drought sensitive. Selection can be made on all the observations at early growth stages. PEG is an important drought inducer for quick screening of germplasm in laboratory conditions to identify drought tolerant genotypes in soybean.

\section{References}

Habtamu, A., Melkamu, Z., Mesfin, M., and and Ermias, E. (2014). Evaluation of highland maize (Zea mays L.) cultivars for polyethylene glycol (PEG) induced moisture stress tolerance at germination and seedling growth stages. Journal of Plant Breeding and Crop Science. 6(7): 7783.

Khodarahmpour, Zahra. (2011). Effect of drought stress induced by polyethylene glycol (PEG) on germination indices in corn (Zea mays L.) hybrids. African journal of Biotechnology. 10(79): 18222-18227.

Kostturkova, G., Todorova, R., Tasheva, K., and Dimitrova, M. 2014. Screening of soybean against water stress mediated through polyethylene glycol. Turkish Journal of Agricultural and Natural Sciences. Special issue 1.

Wu, C., Wang, Q., Xie, B., Wang, Z., Cui, J., and $\mathrm{Hu}, \mathrm{T}$. (2018). Effect of drought and salt stress on seed germination of three leguminous species. African Journal of Biotechnology. 10(78): 17954-17961.

Rajamanickam, V., Ravichandran, L., Parasuraman, B. (2018). Assessment of soybean genotypes for PEG induced drought tolerance at germination and seedling level. Madras Agriculture Journal.105 (1-3): 1-6.

Rana, M., Hasan, M., Bahadur, M., and Islam, M. (2017). Effect of polyethylene 
glycol induced water stress on germination and seedling growth of wheat (Triticum aestivum). The Agriculturists.15(1): 81-91.

Akte, j., Yasmin, S., Bhuiyan, M., Khatun, F., Roy, J., Goswami, K. (2016). In vitro screening of rice genotypes using polyethylene glycol under drought stress. Progressive Agriculture. 27(2): 128-135.

Badr et al., (2020) screening for drought tolerance in maize (Zea mays L.) germplasm using germination and seedling traits under simulated drought conditions. Plants. 9(5): 565.

Chachar, Z., chachar, N., Chachar, Q., Mujtaba, S., Chachar, G. and Chachar. S. (2016). Identification of drought tolerant wheat genotypes under water deficit conditions. International Journal of Research Granthalayh. 4(2): 206-214.

Saha, et al., (2017) selection of drought tolerant wheat genotypes by osmotic stress imposed at germination and early seedling stage. SAARC Journal of Agriculture. 15(2): 177-192.

Koskosidis et al., (2020). Effect of PEG induced drought stress on germination of 10 chickpea (Cicer arientinum L.) genotypes. Notulae Botanicae Horti Agrobotanici Cluj-Napoca. 48(1): 294-304.

Channaoui, et al., (2019). Reaction of some rapeseed (Brassica napus L.) genotypes to different drought stress levels during germination and seedling growth stages. OCL -Oilseeds and Fats, Crops and Lipids.26:23.

Saha, A. and Mandal, S. (2019). Nutritional benefit of soybean and its advancement in research. Sustainable Food Production. 5: 6-16.

Agrawal, D., Billore, S., Sharma, A., Dupare, B., and Srivastava, S. (2013). Soybean: introduction, improvement, and utilization in india- problems and prospectus. Agriculture Research. 2(4): 293-300.

Hidebrand et al., (1986). Soybean (Glycine $\max \quad$ (L.) Merr.). Crops I. Biotechnology in Agriculture and Forestry. 2: 283-308.

Basal, O., Szabo, A. and Veres, S. (2020). Physiology of soybean as affected by PEG- induced drought stress. Current Plant Biology. 22:100-135.

Pavli, O., Foti, C., Skoufogianni, G., Karastergiou, G., Panagou, A. and khah, E. (2020). PEG-induced drought stress during germination: effects on soybean germplasm. Agricultural Research and Technology.23(4): 556250.

Hellal, F. and Abdelly C. (2018). Influence of PEG induced drought stress on molecular and biochemical constituents and seedling growth of Egyptian barley cultivars. Journal of Genetic Engineering and Biotechnology. 16(1): 203-212.

Datta, J., Mondal, T., Banerjee, A. and Mondal, N. (2011). Assessment of drought tolerance of selected wheat cultivars under laboratory condition. Journal of Agricultural Technology. 7(2): 383-393.

Bouslama, M. and Schapaugh, W. (1984). Stress tolerance in soybeans. I. evaluation of three screening techniques for heat and drought tolerance. Crop Science. 24(5): 8351006.

Basal, O., Szabo, A. and Veres, S. (2020). PEG-induced drought stress effect on soybean germination parameters. Journal of Plant Nutrition. 43(12): 1768-1779.

Partheeban, C., Chandrasekhar, C., Jeyakumar P., Ravikesavan, R. and Gnanam, R. (2017). Effect of PEG induced drought stress on seed 
germination and seedling characters of maize (Zea mays L.) genotypes. International Journal of Current Microbiology and Applied Science. 6(5): 1095-1104.

Basha, P., Sudarsanam,G., Reddy, M. and Sankar, N. (2015). Effect of PEG induced water stresson germinationand seedling development of tomato germplasm. International Journal of Recent Scientific Research. 6(5): 4044-4099.

Pratap, V. and Sharma, Y. (2010). Impact of osmotic stress on seed germination and seedling growth in black gram (Phaseolus mungo). Journal of Environmental Biology. 31(5): 721726.

Yagmur, M. and Kaydan, D. (2008). Alleviation of osmotic stress of water and salt in germination and seedling growth of triticale with seed priming treatments. African Journal of Biotechnology.7(13): 2156-2162.

Baloch, M., Dunwell, J., Khakwani, A., Dennett, M., Jatoi, W. and Channa, S. (2012). Assessment of wheat cultivars for drought tolerance via osmotic stress imposed at early seedling growth stages. Journal of Agricultural Research. 50(3): 299-310.

Wijewardana et al., (2019). Water deficit effects on soybean root morphology and early season vogour. Agronomy. 9:836.

Bayu et al., (2005). Water stress affects the germination, emergence and growth of different sorghum cultivars. Ethiopian Journal of Science. 28(2): 119-128.

Munamava, M. and Riddoch I. (2001). Response of three sorghum (Sorghum bicolor L. moench) varieties to soil moisture stress at different developmental stages. South African Journal of Plant and Soil. 18(2): 7579.

Datir, S. and Inamdar, A. (2019). Biochemical responses of wheat cultivars to PEGinduced drought stress. Russian Agricultural Sciences.45: 5-12.

Prisco, et al., (1992). Effect of seed pretreatment on seed germination under water stress condition. Revta Brasil Botany. 15: 31-5.

\section{How to cite this article:}

Sumit N. Deshmukh, Prashant N. Kolhe, Manisha R. Kale, Mrunalini D. Varne and Kiran Pawar. 2020. Evaluation of Drought Effect on Soybean Genotypes Mediated through PEG6000 (Polyethylene Glycol). Int.J.Curr.Microbiol.App.Sci. 9(09): 726-734. doi: https://doi.org/10.20546/ijcmas.2020.909.092 